\title{
Current challenges in pregnancy-related mortality
}

\author{
Charlotte Oyston \\ MB ChB; BMedSci(Hons); DipOMG \\ Registrar, Women's Health, Middlemore Hospital, Auckland, New Zealand \\ $\mathrm{Ph}+64276687560$ \\ c.oyston@auckland.ac.nz
}

Christian F Rueda-Clausen

MD, PhD, FTOS

Postgraduate Clinical Trainee, Department of Medicine, University of Alberta

$\mathrm{Ph}+17809381979$

ruedacla@ualberta.ca

Philip N Baker

BMedSci, BM, BS, DM, FRCOG, FRANZCOG, FMedSci

Pro-Vice-Chancellor and Head of the College of Medicine, Biological Sciences and

Psychology, Dean of Medicine College of Medicine, Biological Sciences and Psychology

University of Leicester. Distinguished National Professor, Chongqing Medical University, China \&

Professor of Maternal and Fetal Health, University of Auckland, New Zealand 


\begin{abstract}
Pregnancy is a normal, healthy state that most women are desirous for at some point in their lives. Sadly, this life-affirming process carries serious risks of death and disability for both mother and offspring. It is estimated that about 830 women die from pregnancy or pregnancy related complications each year. Almost all of these deaths occur in resource-poor countries, and most of them are preventable. Reducing maternal mortality is an ongoing challenge, and care providers, researchers and policy makers must not only identify the key barriers to accessing quality health care, but commit to making maternal health a priority.
\end{abstract}

\title{
Keywords
}

maternal, mortality, death, resource-poor countries, haemorrhage, sepsis, preeclampsia, obstructed labour, unsafe abortion. 


\section{Introduction}

The death of a mother is a catastrophic tragedy which will impact significantly on her children, partner, families and communities left behind. Maternal mortality is highly related to maternal morbidity and long-term disability and complications. It has been calculated that for every woman who dies from a pregnancy-related cause there are an average of 16.5 cases of significant maternal illness or disability related to pregnancy. Despite advances in healthcare technologies in some parts of the world, globally around $80 \%$ of maternal deaths are from preventable causes. This review will outline the terminology used to describe maternal mortality, the aetiologies of maternal mortality and summarise some barriers to reducing maternal mortality.

\section{Definitions}

Measurement of maternal mortality is a well-accepted vital statistic that provides a broad diagnostic of the maternal health condition of any given region, as well as the overall effectiveness of health systems. Consistency in the terminology used is crucial when discussing the global burden of and trends in maternal mortality. In the International Statistical Classification of Diseases and Related Health Problems $10^{\text {th }}$ edition (ICD-10), the World Health Organization defines maternal mortality as:

The death of a woman while pregnant or within 42 days of the end of pregnancy, irrespective of the duration and site of the pregnancy, from any cause related to or aggravated by the pregnancy or its management but not from accidental or incidental causes.

Deaths are further classified as either direct or indirect. Direct maternal deaths are those resulting from obstetric complications (e.g. postpartum haemorrhage), interventions (e.g. anaesthetic complications), maternal suicide, omissions or incorrect treatment. Indirect maternal deaths are deaths not caused by obstetric complications, but by pre-existing conditions which are exacerbated by pregnancy (e.g. heart failure precipitated by pregnancy in the presence of preexisting aortic stenosis). Other definitions in the ICD-10 include pregnancy-related death 
(maternal death during pregnancy or within 42 days of the end of pregnancy), and later maternal death (death resulting from direct or indirect causes occurring between day 42 and 1 year after the end of pregnancy). Collecting data on pregnancy related death may be important in resourcepoor countries where accurate information regarding cause of death is not available. Conversely, information on later maternal deaths may be more important in resource-rich countries, where life-sustaining technologies can allow very sick women to live longer than 6 weeks post-delivery (e.g. a woman suffering acute fatty liver of pregnancy who dies following liver transplantation 3 months following pregnancy).

\section{Measures of maternal Mortality}

Estimates of maternal mortality are influenced by both the chance of a woman being pregnant (i.e. the fertility rate) and the chance of death in a pregnancy. The maternal mortality ratio (MMR) takes into consideration both of these attributes and is calculated as

$$
\begin{gathered}
M M R=\frac{\text { number of }(\text { direct } \text { or } \text { indirect }) \text { maternal deaths }}{100,000 \text { live births in the same population }} \\
\text { over the same time period }
\end{gathered}
$$

This definition is important, as it is the calculation used for international comparison. In contrast, the maternal mortality rate (MMRate) does not consider the fertility rate, and is calculated as:

$$
\text { MMRate }=\frac{\text { maternal deaths in a population over a given period }}{100,000 \text { women aged } 15-49 \text { years }}
$$

Women living in resource-poor countries not only have a higher risk of death in pregnancy, but have (on average) many more pregnancies than women in resource-rich countries. Consequently, their lifetime risk of death due to pregnancy related complications is higher. This is accounted for 
by the lifetime risk (LR) of maternal death, which describes the probability that a 15-year-old woman will eventually die from a pregnancy related cause.

\section{Limitations in calculating maternal mortality rates and cause of death}

Data used to estimate maternal mortality can be derived from civil registration of births and deaths, household surveys, census data, reproductive-age mortality studies and verbal autopsy (lay respondents are interviewed on the signs and symptoms of the deceased before death). Obtaining high-quality data on maternal mortality may be challenging, especially in poorly resourced settings. In 2015, the United Nations Maternal Mortality Estimation Inter-Agency Group reported that there was no recent, good quality data on maternal mortality for 55 of 171 countries considered. Inconsistent or mis-classification of maternal deaths also impedes the ability to accurately describe and compare statistics on maternal mortality amongst regions. While some civil registration systems use the ICD-10 to classify causes of death, the use of this system is not consistent between all countries. Obtaining data where civil registration is incomplete, pregnancy status or cause of death is unknown is especially challenging, and likely to obscure true rates of maternal mortality or causes of maternal mortality especially in resource-poor settings. Even in well-resourced countries, relying on civil registration data alone is likely to result in an underestimate of true maternal mortality: in the 2011 In report of the Centre for Maternal and Child Enquiries (CMACE), 60\% more deaths were ascertained by the enquiry compared civil registration alone.

\section{Current estimates and trends of maternal mortality}

In 2015 , the global maternal mortality ratio was estimated to be 216 maternal deaths per 100,000 live births, and the global lifetime risk of maternal death estimated to be 1:180. The burden of maternal mortality, however, is not disturbed evenly worldwide: $99 \%$ of maternal deaths occur in resource-poor countries, with $88 \%$ of maternal deaths occurring in Sub-Saharan Africa and Southern Asia. The MMR is substantially higher in resource-poor, compared to resource-rich countries: 239 vs. 12 deaths per 100,000 live births (in comparison, the most recent estimates of the UK MMR is 4.65 deaths per 100,000 live births). The lifetime risk of maternal mortality is 1 in 
36 for women in sub-Saharan Africa compared to vs 1 in 4,900 for women in resource-rich countries. As well as global disparities, there are disparities between women of differing demographics living in the same country. The most susceptible populations are those with low income or socioeconomic status, women living in rural areas and those who are younger than 15 years old; complications in pregnancy and childbirth are the leading cause of death among adolescent girls in most resource-poor countries.

\section{The aetiologies of maternal mortality}

A recent WHO systematic analysis has shown that globally, almost three-quarters of maternal death are attributable to a direct cause. Overall, haemorrhage, hypertensive disorders and sepsis account for more than $50 \%$ of maternal deaths. The most prevalent individual aetiologies of maternal mortality are:

- haemorrhage - $27 \%$

- hypertensive disorders - $14 \%$

- $\quad$ sepsis - $11 \%$

- unsafe abortion - $8 \%$

- embolism $-3 \%$

In comparison, in resource-rich countries, most maternal deaths are due to indirect causes. In the UK, for the triennium of $2012-2014,60 \%$ of maternal deaths were due to indirect causes and the leading causes of maternal death were:

cardiac disease - $26 \%$

indirect neurologic conditions - $11 \%$

thrombosis and thromboembolism - 10\%

amniotic fluid embolism - 8\%

maternal suicide - $7 \%$ 
The more common aetiologies are discussed below, however a detailed discussion of all aetiologies is beyond the scope of this review. Further information can be found in the suggested readings.

\section{Postpartum haemorrhage}

Postpartum haemorrhage (PPH) causes more deaths than any other aetiology and disproportionately affects women giving birth in resource-poor countries. It is likely that the prevalence of $\mathrm{PPH}$ is underestimated, as visual estimates of blood loss are notoriously inaccurate and constitute a major obstacle in both the diagnosis and study of PPH. The most common cause of $\mathrm{PPH}$ is uterine atony. The use of uterotonic medications to increase myometrial tone, compress blood vessels and stop haemorrhage is key to treating PPH. It is a WHO and RCOG recommendation that all women giving birth have access to uterotonic administered by a health worker trained in its use for the prevention of $\mathrm{PPH}$. This recommendation is not met in many cases, especially in sub-Saharan Africa; where more than half of the women give birth do so without access to a skilled birth attendant. Over a 10-year period, if all women giving birth had access to uterotonics (such as misoprostol and oxytocin), an estimated 41 million cases of PPH would be prevented and 1.4 million lives saved.

PPH also contributes to maternal mortality in the resource-rich countries. Between $2012-2014$, $\mathrm{PPH}$ was the fourth most common direct cause of maternal death in the UK (5.6 deaths/million maternities). Despite maternal death being a relatively rare outcome in the UK, there is a need to remain vigilant, adhere to management guidelines, and undergo regular drills and skill updates to ensure that their care for women is optimal. This is especially important due to the rising incidence of PPH, perhaps due to changing maternal demographic (older and more obese), trends toward increasing interventions (induction of labour, caesarean delivery and consequently increased rates of abnormal placentation), and increased rates of multiple pregnancy.

\section{Pre-eclampsia / Eclampsia}

Pre-eclampsia is estimated to affect up to $10 \%$ of pregnancies, and contributes significantly to maternal mortality worldwide, as well as being a significant cause of perinatal morbidity and 
mortality. The majority of maternal deaths due to pre-eclampsia occur in resource-poor countries. Death may result from a variety of complications, including cerebral (intracerebral bleed, oedema, convulsions), pulmonary (ARDS, oedema), or liver (rupture, necrosis) pathologies. The onset of pre-eclampsia may be insidious, the course unpredictable, and deterioration rapid. In wellresourced countries many cases are diagnosed on routine antenatal screening at a stage when women are asymptomatic. When antenatal care is not accessible, women and their families may not realise that there is a problem until the disease is advanced. Management of pre-eclampsia / eclampsia is limited to observation and supportive care (close monitoring of disease progression, the use of magnesium for prevention of eclampsia and more stringent control of blood pressure to prevent cerebral vascular accidents) with timely delivery when maternal or fetal condition deteriorates. Access to facilities which can provide this management is limited in resource-poor countries, and undoubtedly a contributing factor to the massive mortality pre-eclampsia causes in these societies. Although absolute numbers are lower, pre-eclampsia and eclampsia still kill women in the resource-rich world. Many of these deaths are preventable: in particular, failure to effectively lower blood pressure may result in avoidable death from intracranial haemorrhage.

\section{Sepsis and infection}

Puerperal infection and sepsis from the reproductive tract are significant contributors to maternal mortality. As for other causes of maternal mortality, infection disproportionately affects those in resource-poor countries, contributing to $12 \%$ of maternal mortality in Asia, but only $2 \%$ of maternal mortality in resource-rich countries. It is in the prevention of puerperal infection that the most significant gains have been made towards reducing maternal mortality in resource-rich countries. Prior to the advent of antimicrobial agents and aseptic technique, puerperal infection was one of the leading causes of maternal mortality. In the UK, during the nineteenth century, 3 women per 1000 deliveries could expect to die from puerperal infection; this reduced dramatically to 1 death per 100,000 deliveries in the early 2000's but now appears to be increasing. Reductions in maternal mortality can be made in resource-poor settings by increasing access to clean water, clean birthing conditions, and access to skilled attendants during labour and the 
puerperium. Other factors important to reducing mortality from infection include improving maternal nutrition and improving access to clean, well-resourced health care centres.

Despite advances in prevention, diagnosis and antimicrobial therapy, sepsis and infection remain leading causes of maternal death in resource-rich countries. In particular, in the UK, deaths attributable to Group A Streptococcal septicaemia are increasing. This trend is a sinister reminder that scrupulous hygiene is required at all times in the care of women in pregnancy and postnatally. Deterioration and death from sepsis may occur in hours, even in women who were previously healthy. Early diagnosis, resuscitation and administration of antibiotics are key to preventing deaths from sepsis, and national guidelines for the identification and treatment of women with sepsis in pregnancy or postpartum are available.

\section{Unsafe abortion}

The rate of maternal death from unsafe abortion is significantly higher than for abortion in an appropriate medical setting. Ninety-nine percent of deaths that occur as a result of abortion are from unsafe abortion, provided by unskilled providers in unsterile conditions. The main causes of death from unsafe abortion are haemorrhage and infection. Determining a true estimate of maternal deaths from abortion is inherently challenging. Not surprisingly, the incidence of unsafe abortion correlates with the restrictiveness of abortion law, and as a result procurement of abortion will be underreported in countries with the highest rates of unsafe abortion.

Improving access to effective, culturally acceptable contraception is key to reducing unwanted pregnancy. However, no contraception is entirely effective, and access to safe abortion will remain crucial to reducing maternal mortality. This will be difficult to achieve in countries where entrenched beliefs influence the law and override the right of women to access safe medical services. Although the maternal mortality rate was not affected by the introduction of measures to prohibit abortion in countries such as Chile, El Salvador and Nicaragua, the obvious rebuttal to this is that the rates of maternal mortality due to abortion may be under-reported where the practice is illegal. Making abortion services illegal does not reduce the rate at which women seek 
abortion, but it does reduce the rate of safe abortion, and increase the rate at which women die from abortion.

\section{Obstructed labour}

Obstructed labour occurs in an estimated $5-10 \%$ of births but has been estimated to account for about $8 \%$ of maternal deaths worldwide. Without appropriate and timely management, obstructed labour results in death due to haemorrhage, sepsis or uterine rupture. These terminal conditions may be more likely to be recorded as a cause of death, as opposed to 'obstructed labour', and this may be the reason that some reports do not list obstructed labour as a cause of maternal mortality. The incidence of uterine rupture is increased amongst those who are multiparous and live in remote regions. In such settings the incidence of uterine rupture may be as high as 1:69 deliveries (rural Nigeria). Lack of access to functional maternity services (including skilled birthing attendants), lack of access to safe operative delivery, and late presentation to functional maternity services. The use of partograms for recognition of abnormal labour is one cheap strategy that could potentially facilitate a standard of labour management in resource-poor countries. This strategy, whilst promising, needs to be introduced and used in a culturally acceptable manner, and will only work when there are adequate trained birth attendants to assess women in labour, and adequate infrastructure to organise timely transfer to larger centres which have the resources to provide safe operative delivery.

\section{HIV-AIDS}

The risk of maternal death higher in HIV positive women, although it is not entirely clear why this is, as pregnancy itself does not seem to be associated with disease progression in either treated or untreated women. It is likely that the increased mortality can be attributed to poorer outcomes associated with opportunistic and puerperal infections. The findings of the 2010 South African Confidential Enquiry into Maternal Deaths support this hypothesis. In this report, the most common causes of death amongst HIV positive women were AIDS, pneumonia, TB and meningitis, and women infected with HIV were also more likely to die from genital tract sepsis or abortion complications compared with HIV negative women. 
Untangling the true estimate of indirect deaths due to HIV is challenging. In areas where HIV is prevalent, there will not only be more cases of HIV attributable maternal death (i.e. HIV as an indirect cause of maternal death), but also more incidental deaths of women with HIV. For resource-poor regions, the proportion of maternal deaths attributable to HIV is reported as $6 \%$. In areas where HIV has reached epidemic proportions (e.g. South Africa and parts of sub-Saharan Africa) HIV attributable deaths account for up to $67 \%$ of all maternal deaths. Reduction in HIV related maternal mortality in the African continent will only be achieved when all citizens have access to diagnostic screening and anti-retroviral medications which are the standard of care in resource-rich nations.

\section{Cardiac Disease}

Maternal cardiac disease has been the leading cause of maternal death in the UK since 2000. In the 2012-2014 triennium, the most common diagnoses for women who died from a cardiac condition were: a sudden arrhythmia with a morphologically normal heart (31\% of cardiac deaths), ischemia ( $22 \%$ of cardiac deaths) and cardiomyopathy / myocardial disease ( $18 \%$ of cardiac deaths). More than three-quarters of the women who died of cardiac problems were not known to have pre-existing cardiac problem, although most of them had other pre-existing medical conditions. Therefore, it is prudent that women at risk of cardiac disease (for example those who are obese, hypertensive, diabetic, or smokers) should have a pre-conception cardiac risk assessment, and be counselled accordingly on the risks of pregnancy.

The most recent report of Mothers and Babies: Reducing Risk through Audits and Confidential Enquiries (MBRRACE) - UK highlighted that delay in diagnosis and treatment contributed significantly to maternal mortality from cardiac disease. The report emphasises that there must be a low-threshold for further investigation in women presenting with cardiovascular or respiratory symptoms, and that essential investigations and therapies should not be withheld due to pregnancy or breastfeeding. Review by senior clinicians (obstetric and cardiology) and a multidisciplinary approach is crucial to accurately diagnosing and effectively managing cardiac disease in pregnancy and the puerperium. It should also be recognised that traditional means of 
referral and communication between teams may be too slow in pregnancy. Therefore, consideration should be given to measures such as joint obstetric-cardiac clinics (or face-to-face meetings between specialists), the formation of multidisciplinary care plans, and recording information from all specialties in the woman's hand held pregnancy notes, which may reduce the risks associated with inadequate communication between specialities.

\section{Maternal Obesity}

The global obesity epidemic continues to gain attention as a mayor public health issue, particularly in young women of reproductive age in whom obesity is the most prevalent chronic cardiometabolic risk factor. Obesity in pregnancy includes women who are obese (body mass index BMI greater than $30 \mathrm{~kg} / \mathrm{m}^{2}$ ) before conception as well as those with normal BMI at conception but excess weight gain during pregnancy. There are many adverse obstetric outcomes associated with a greater maternal mortality and with maternal obesity, including prepartum complications (two-fold increase risk of spontaneous abortion and stillbirth, hypertensive disorders of pregnancy - estimated two-fold increment for every 5 to $7 \mathrm{~kg} / \mathrm{m}^{2}$ increment in BMI, and a 2-3-fold increase in fetal macrosomia), intrapartum complications (greater than two-fold increase risk of caesarean delivery, significantly longer labour times for both nulliparous and multiparous women, increased incidence of significant perineal tear if delivered vaginally and increase prevalence of surgical complications) and postpartum complications (two-fold increase in post-partum bleeding and thromboembolic events).

\section{Reducing maternal mortality}

In 2000 , members of the United Nations pledged to reduce maternal mortality ratio to $75 \%$ of the 1990 levels, by 2015. This objective was known as Millennium Development Goal (MDG) 5a. Although the global MMR fell by $44 \%$ (well short of the $75 \%$ target) it is encouraging that all MDG regions experienced reductions in maternal mortality. Furthermore, the decline in MMR appeared to become more rapid from 2000 onwards, perhaps due to a number of additional initiatives employed in the countdown to the 2015 deadline. Building on this momentum, a new agenda has 
been set as part of the Sustainable Development Goals (SDG) to reduce the global MMR to below 70 per 100,000 live births by 2030 , and for no country to have a rate of more than double the global average. Further information is available in the WHO publication Strategies Toward Ending Preventable Maternal Mortality (see below for full reference).

A list of interventions that should be available to all women during pregnancy, delivery and postpartum is given in Table 1. These interventions are more easily accessible in resource-rich countries, where almost every woman has at least four antenatal care visits, is attended by a skilled health worker during childbirth and receives postpartum education and follow-up. In contrast, more than half of all pregnant women in resource-poor countries receive less than four antenatal visits and at least a third of women do not have a trained assistant to assist in childbirth. In order to improve maternal mortality in resource-poor countries, we need to identify and remove the barriers that limit access to health services. Some barriers will be common amongst countries, such as: a lack of knowledgeable staff, technology or medicines to implement evidence based practise, or a lack of transport, poor or absent road access and physical distance of rural communities to healthcare services. In addition to these, each country will have its own specific geographic, socio-cultural and political barriers. The changes required to reduce maternal mortality will not happen simply through the financial or political influence of resource-rich countries - although these will be required as well. To reduce maternal mortality, each individual country needs to make a political commitment and financial investment, and prioritise the uptake of evidence based practise and focus on quality care.

Training skilled practitioners to work in areas of need is crucial to reducing maternal mortality. In the absence of skilled attendants, recognising an evolving emergency situation is not easy; by the time a woman or her family realise there is a problem, it may be too late. In order to reduce maternal mortality, health systems and the health workforce capacity will need strengthening and support. Increased access to antenatal care and skilled obstetric providers trained in emergency obstetric care must be available to all pregnant women. Workforce strategies should include plans to build a cadre of skilled birth attendants and community health workers to care for 
pregnant women and their children. One strategy that could be employed is for resource-poor countries to establish incentive programs to retain clinical staff and repatriate former staff. Resource-rich countries should be encouraged to form health education partnerships, and discouraged from actively recruiting trained individuals from resource-poor countries.

Research in maternal mortality has focused on the description of the problem and identification of risk factors. This research is important, and has advanced our understanding of the causes of and trends in maternal mortality. It is important to continue this research to evaluate the efficiency of health services, assess the response to policy or guideline implementation, and identify new areas of need. In addition, new directions for research should include the development of novel therapies for conditions such as pre-eclampsia, and optimising the implementation of evidence based practises in culturally and geographically diverse settings. In order to facilitate these research goals, governments and other organizations need to increase the amount of resources available for these purposes, particularly in low-income countries.

In resource-rich countries, where we experience the privilege of greater resources, evidence based training systems, comprehensive infrastructure and stable government; many mothers still die preventable deaths. In many cases a deficiency in knowledge or skills, a failure to follow best practice, or a lack of timely access to specialist care contributes to these deaths. It is crucial that momentum is not lost and that the old messages - for example maintaining scrupulous hygiene are repeated and enforced in our own practise, as well as in the training of as new generations of carers. The development of institution-wide and nation-wide evidence based guidelines is encouraged. These should be subject to regular review, and used to evaluate practice by clinical audit.

\section{Conclusion}

Hundreds of thousands of women die every year due to complications arising from pregnancy and childbirth. Knowing the magnitude of this problem is not enough; we need to put a face to each one of those numbers and understand the underlying factors that led to the deaths of the 
women. Irrespective of where they are born or live, women should have access to reliable contraception choices, antenatal care in pregnancy, skilled care during childbirth, care and support in the weeks after childbirth, and the option of safe termination of pregnancy. It is heartbreaking to consider that most maternal deaths - even those occurring in resource-rich countries could have been avoided if adequate care were available, accessible or accessed.

\section{Self-assessment questions}

Maternal death may be categorised as direct or indirect - what are the definitions of each?

Provide five examples each of a direct cause and an indirect cause of maternal death.

What is the maternal mortality ratio (MMR) and how is it calculated?

Well-resourced countries have a much lower MMR than that seen in resource-poor countries. List two major causes of preventable maternal death in resource-poor countries and briefly describe a possible solution for each.

\section{Further reading}

Alkema L, Chou D, Hogan D et al. Global, regional, and national levels and trends in maternal mortality between 1990 and 2015, with scenario-based projections to 2030: a systematic analysis by the UN Maternal Mortality Estimation Inter-Agency Group. Lancet 2016; 387 (10017): 462-74.

Knight M, Nair M, Tuffnell D, et al. (Eds) on behalf of MBRRACE-UK. Saving Lives, Improving Mothers' care - Surveillance of maternal deaths in the UK 2012-2014 and lessons learned to inform maternal care from the UK and Ireland Confidential Enquiries into Maternal Deaths and Morbidity 2009-2014. Oxford: National Perinatal Epidemiology Unit, University of Oxford 2016.

Royal College of Obstetricians and Gynaecologists. Cardiac Disease and Pregnancy (Good Practice No.13). Published: 22/06/2011. Available online at http://www.rcog.org.uk/en/guidelinesresearch-services/guidelines/good-practice-13 
Royal College of Obstetricians and Gynaecologists. Thrombosis and Embolism during Pregnancy and the Puerperium, Reducing the Risk (green-top Guideline No. 37a). Available online at http://www.rcog.org.uk/en/guidelines-research-services/guidelines/gtg37a

World Health Organization. Strategies for Ending Preventable Maternal Mortality. Published February 2015. Available online at http://www.who.int/reproductivehealth/publications/monitoring/maternal-mortality-2015/en

World Health Organization. Trends in maternal mortality: 1990 to 2015 . Estimates by WHO, UNICEF, UNFPA, World Bank Group and the United Nations Population Division. Published November 2015. Available online at http://www.who.int/reproductivehealth/publications/monitoring/maternal-mortality-2015/en 
Table1 Recommended Interventions for Improving Maternal and Newborn Health

\begin{tabular}{|c|c|c|c|}
\hline & $\begin{array}{l}\text { Routine care } \\
\text { (Offered to all women and babies) }\end{array}$ & $\begin{array}{l}\text { Additional care } \\
\text { (For women and babies } \\
\text { with moderately severe } \\
\text { diseases and } \\
\text { complications) }\end{array}$ & $\begin{array}{l}\text { Specialized care } \\
\text { (for women and } \\
\text { babies with severe } \\
\text { diseases and } \\
\text { complications) }\end{array}$ \\
\hline 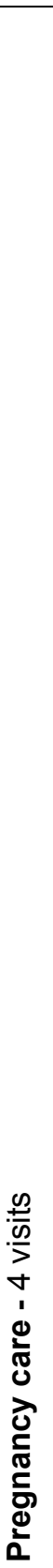 & $\begin{array}{l}\text { - Confirmation of pregnancy } \\
\text { - Monitoring of progress of pregnancy and } \\
\text { assessment of maternal and fetal well- } \\
\text { being } \\
\text { - Screening for (anaemia, hypertensive } \\
\text { disorders, bleeding, malpresentations, } \\
\text { multiple pregnancy) } \\
\text { - Respond to other reported complaints. } \\
\text { - Tetanus immunization, anaemia } \\
\text { prevention and control (iron and folic acid } \\
\text { supplementation) } \\
\text { - Information and counselling on self care } \\
\text { at home, nutrition, safer sex, breastfeeding, } \\
\text { family planning, healthy lifestyle } \\
\text { - Birth planning, advice on danger signs } \\
\text { and emergency preparedness } \\
\text { - Recording and reporting } \\
\text { - Syphilis testing }\end{array}$ & $\begin{array}{l}\text { - Treatment of mild to } \\
\text { moderate pregnancy } \\
\text { complications: } \\
\text { - mild to moderate anaemia } \\
\text { - urinary tract infection } \\
\text { - vaginal infection } \\
\text { - Post abortion care and } \\
\text { family planning } \\
\text { - Pre-referral treatment of } \\
\text { severe complications } \\
\text { - pre-eclampsia } \\
\text { - eclampsia } \\
\text { - bleeding } \\
\text { - infection } \\
\text { - complicated abortion } \\
\text { - Support for women with } \\
\text { special needs e.g. } \\
\text { adolescents, women living } \\
\text { with violence } \\
\text { - Treatment of syphilis } \\
\text { - woman and her partner) }\end{array}$ & $\begin{array}{l}\text { - Treatment of } \\
\text { severe pregnancy } \\
\text { complications: } \\
\text { - anaemia } \\
\text { - severe pre- } \\
\text { eclampsia } \\
\text { - eclampsia } \\
\text { - bleeding } \\
\text { - infection } \\
\text { - other medical } \\
\text { complications } \\
\text { - Treatment of } \\
\text { abortion } \\
\text { complications }\end{array}$ \\
\hline
\end{tabular}




\begin{tabular}{|c|c|c|c|}
\hline 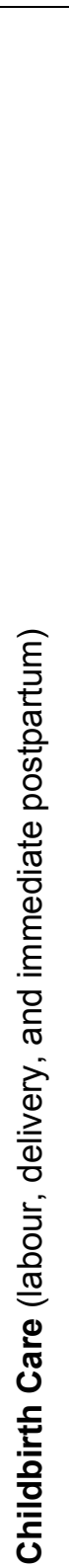 & $\begin{array}{l}\text { - Care during labour and delivery } \\
\text { - Diagnosis of labour } \\
\text { - Detection of malpresentations, prolonged } \\
\text { and/or obstructed labour, hypertension, } \\
\text { bleeding, and infection. } \\
\text { - Delivery and immediate care of the } \\
\text { newborn baby, initiation of breastfeeding } \\
\text { - Newborn resuscitation } \\
\text { - Active management of third stage of } \\
\text { labour } \\
\text { - Immediate postnatal care of mother } \\
\text { - Treatment of moderate post- } \\
\text { haemorrhagic anaemia } \\
\text { - Information and counselling on home self } \\
\text { care, nutrition, safe sex, breast care and } \\
\text { family planning } \\
\text { - Postnatal care planning, advice on danger } \\
\text { signs and emergency preparedness } \\
\text { Recording and reporting }\end{array}$ & $\begin{array}{l}\text { - Treatment of } \\
\text { abnormalities and } \\
\text { complications (e.g. } \\
\text { prolonged labour, vacuum } \\
\text { extraction; breech } \\
\text { presentation, episiotomy, } \\
\text { repair of genital tears, } \\
\text { manual removal of } \\
\text { placenta) } \\
\text { - Pre-referral management } \\
\text { of serious complications } \\
\text { (e.g. obstructed labour, } \\
\text { fetal distress, preterm } \\
\text { labour, severe peri- and } \\
\text { postpartum haemorrhage) } \\
\text { • Emergency management } \\
\text { of complications if birth } \\
\text { imminent } \\
\text { - Support for the family if } \\
\text { maternal death }\end{array}$ & $\begin{array}{l}\text { - Treatment of } \\
\text { severe complications } \\
\text { in childbirth and in } \\
\text { the immediate } \\
\text { postpartum period, } \\
\text { including caesarean } \\
\text { section, blood } \\
\text { transfusion and } \\
\text { hysterectomy): } \\
\text { - obstructed labour } \\
\text { - malpresentations } \\
\text { - eclampsia } \\
\text { - severe infection } \\
\text { - bleeding } \\
\text { - Induction and } \\
\text { augmentation of } \\
\text { labour }\end{array}$ \\
\hline
\end{tabular}




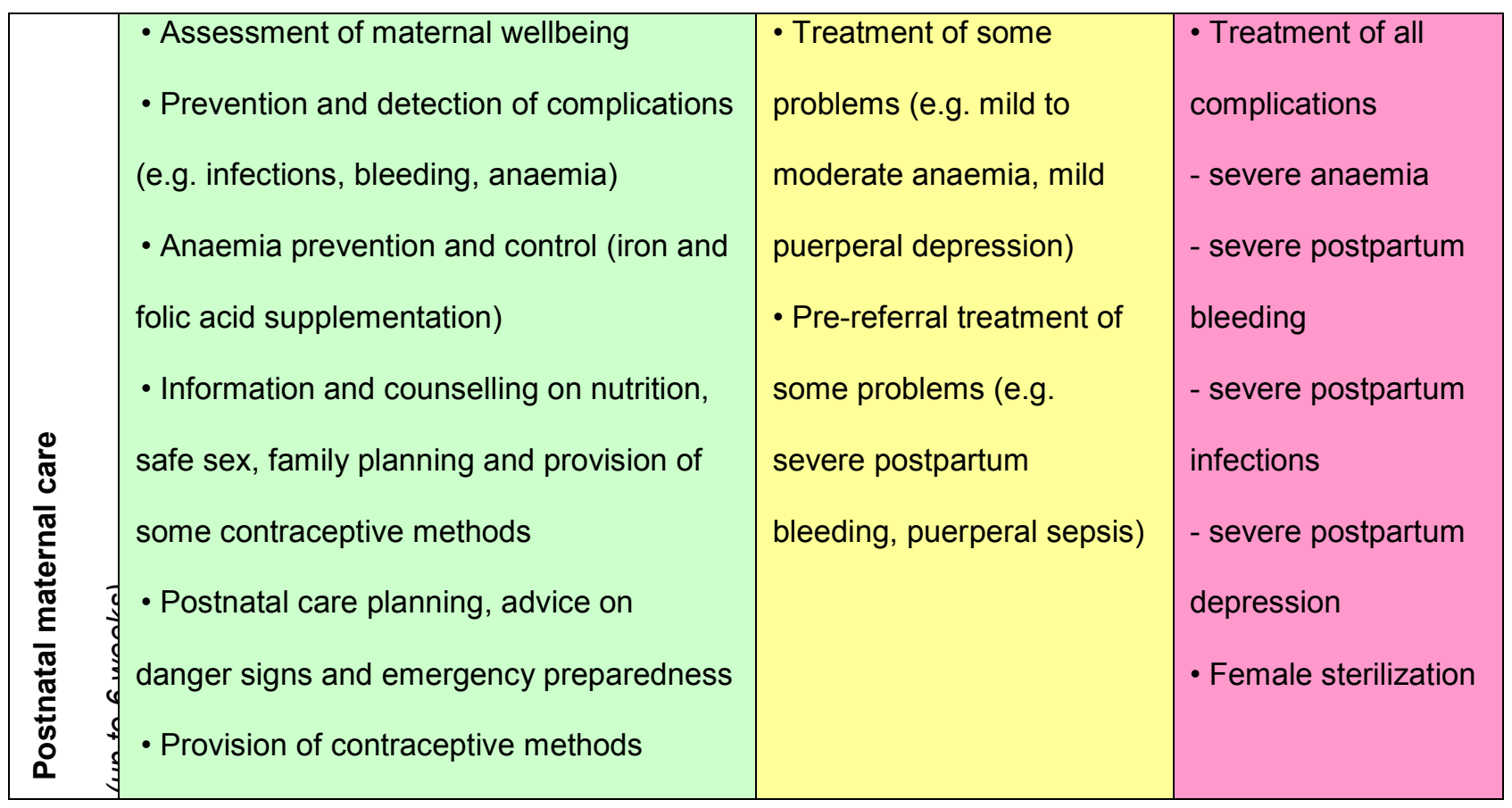




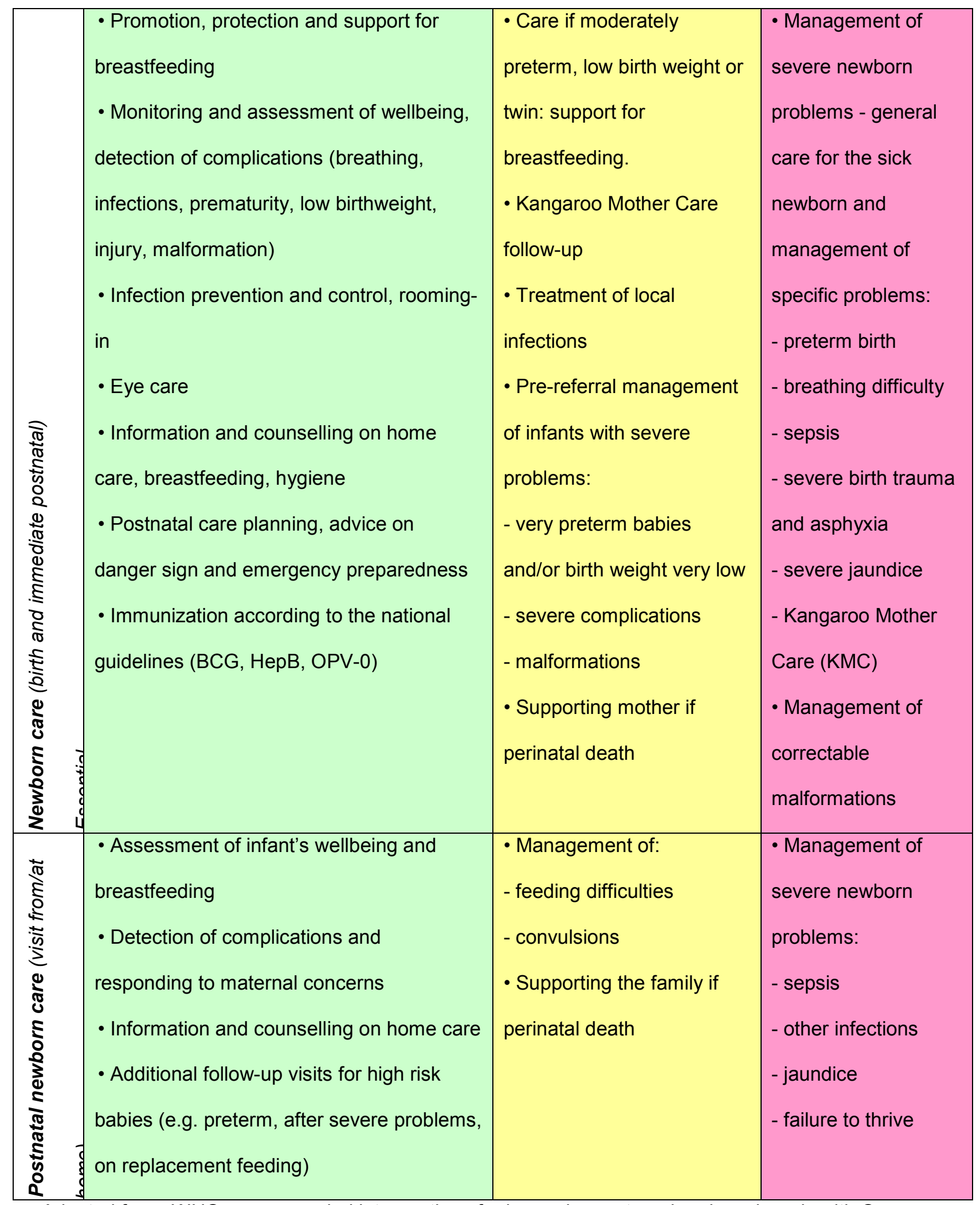

Adapted from: WHO recommended interventions for improving maternal and newborn health $(\odot$ World Health Organization 2009 